\title{
Implications of coal disappearance from the energy mix in Romania
}

\author{
Izabela-Maria Apostu ${ }^{1 *}$, Maria Lazar ${ }^{1}$, and Florin Faur ${ }^{1}$ \\ ${ }^{1}$ University of Petroşani, Department of Environmental Engineering and Geology, University Street \\ no. 20, Petroșani, Romania
}

\begin{abstract}
The firm commitment of the European Union (EU) to fully implement the 2030 Agenda requires the Member States to find and implement solutions to meet global targets, including ensuring clean and affordable energy. The EU encourages the elimination of coal from the energy mix in order to quantitatively reduce emissions and the impact on the environment and human health. Romania attaches great importance to the 2030 Agenda and understands that developing the national economy, increasing the quality of life, and caring for the environment are inextricably linked to the development and modernization of the energy system, for which the National Energy Strategy 2019-2030 was developed. According to it, in the perspective of 2050, Romania will be based on a diversified, balanced, and modern energy mix through clean technologies. But what if coal would disappear from the energy mix? The causes of the disappearance of coal from the energy mix could be represented by global or national policies or the depletion of known exploitable reserves, the latter being a less probable variant. In this paper, we aim to highlight and analyze some scenarios related to the possibilities of replacing coal in the energy mix, which would change the perspectives.
\end{abstract}

\section{Introduction}

Coal is an extremely important fossil fuel for the economical development of many countries, being widely used for the production of thermal and electrical energy by burning it in thermal power plants. Coal is known as the first fuel used during the industrial revolution. It has always been an affordable energy resource, which has encouraged, to some extent, its irrational exploitation. Coal, like all geological resources, is a resource that is difficult to regenerate due to the fact that it is formed in geological periods of time (or practically non-renewable if we refer to the duration of our lives and future generations).

The coal mining sector has attracted the attention of specialists through the negative impact it has on the environment. Climate change, erosion and desertification, soil, water, and air pollution, depletion of tropical forest ecosystems and wetlands, extinction or endangerment of a large number of terrestrial or aquatic plant and animal species, accelerated depletion of non-renewable natural resources have begun to have negative,

\footnotetext{
*Corresponding author: izabelaapostu@upet.ro
} 
measurable effects on the socio-economic development and quality of life of people in large areas of the planet [1].

Mining has participated and is largely involved in the economic development of society, but it has also created major differences in terms of social class and standard of living of the world's population. Thus, in the idea of achieving a balance on the development of nations and ensuring a decent life for all people, by reducing poverty, both for present and future generations, the idea of sustainable development of society occurred.

The sustainable development concept has emerged at a time when the environmental issues have been at the forefront of political debates, leading to increased public awareness, recognizing that the Earth has a limited capacity to meet the growing demand of natural resources and absorb the destructive effects of their use.

The history of the sustainable development concept began about half a century ago and has had the following path:

1972 - elaboration of the Meadows Report "Growth Limits" of the Club of Rome stating that "if current world population growth, industrialization, environmental contamination, food production, and resource depletion are maintained, this planet will reach the limits of growth in the next 100 years" [2].

1987 - publication of the Brundtland Report "Our Common Future" by the World Commission on Environment and Development which defined the sustainable development concept as: "development that seeks to meet the needs of the present, without compromising the ability of future generations to meet their own needs" [3].

1992 - adoption of Agenda 21: "An action program for sustainable development" at the United Nations Conference on Environment and Development in Rio de Janeiro [4].

2002 - adoption of the Johannesburg Declaration on Sustainable Development, which highlighted the importance of sustainable development at the international level and the link between poverty, the environment, and the use of resources [5].

2007 - signing of the Treaty of Lisbon amending the Treaty on European Union and the Treaty establishing the European Community [6].

2015 - adoption of the 2030 Agenda for Sustainable Development by all Member States of the United Nations (UN). It is based on 17 sustainable development goals which are an urgent call to developed and developing countries to eliminate poverty, inequality, improve health, education, economy, etc. [7].

2019 - 2021 - following from the 2030 Agenda, more strategies were developed by the European Commission, two of them being representative for this study, namely the strategic action called European Green Deal - A roadmap for Europe to become climate neutral by 2050 and the European Green Deal Investment Plan and Just Transition Mechanism, a plan for financing the green transition.

European Green Deal is a set of initiatives and policies which aim to make Europe the first climate neutral continent in the world by 2050 .

The main goals of the European - Green Deal are [8]:

- $\quad$ zero emissions of greenhouse gases by 2050;

- $\quad$ economic growth is decoupled from resource use;

- no person and no place is left behind.

The areas of action of the European - Green Deal have been effectively designed as directions for modern legislation to be developed and updated in order to protect the environment. The action plan aims to move to a circular economy (Figure 1), reduce pollution and restore biodiversity by investing in clean technologies, support for innovation in the industrial sector, new less polluting, cheaper and healthier modes of transport, decarbonization of the energy sector, improving the energy efficiency of buildings, working with international partners to improve global environmental standards [9]. 


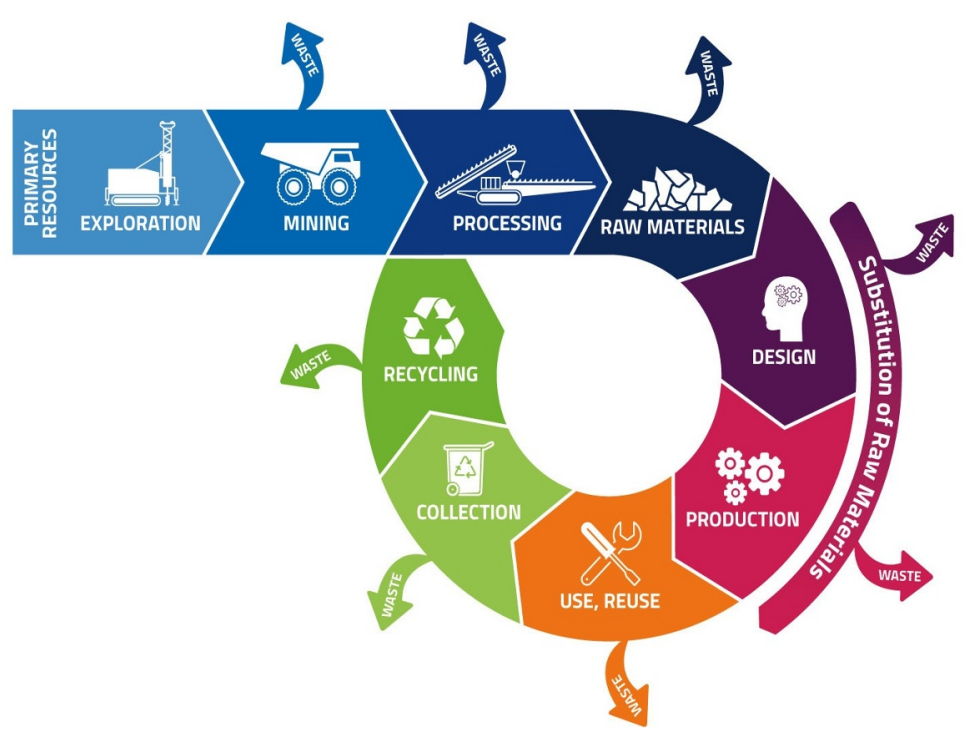

Fig. 1. Circular economy [9].

Europe's transition to a sustainable economy means significant investment efforts across all sectors. The European Green Deal Investment Plan will mobilize EU funding and create an enabling framework to facilitate and stimulate the public and private investments needed for the transition to a climate-neutral, green, competitive and inclusive economy. The Just Transition Mechanism (JTM) is a key tool to ensure that the transition towards a climateneutral economy happens in a just manner, leaving no one behind.

All global actions developed are meant to improve the quality of the environment and health and to ensure sustainable and equitable development of the society. As coal has a major negative impacts and its elimination from the energy mix is being discussed, the possibilities of its replacement have been analyzed in the present paper. Thus, the paper presents 3 possible scenarios related to the situation of the disappearance of coal from the Romanian energy mix, one of which is favorable consisting of replacing coal with renewable energy sources with close to zero emissions, one unfavorable consisting of replacing coal with economically viable sources, but generating emissions at a lower level, and one undesirable when there is an impossibility to cover the energy demand from the existing resources and the country becomes dependent on imports.

\section{Materials and methods}

Sustainable development aims to continuously improve the quality of life and well-being of present and future generations, by promoting the reduction of human ecological footprint, intergenerational equity, and maintaining economic efficiency. The elaborated reports aim at restoring and maintaining a rational, long-term balance between economic development, and the integrity of the natural environment in forms understood and accepted by society.

\subsection{Sustainable development in the coal-mining sector}

According to the definition of sustainable development, mining, which is one of the engines of the development of society, is not classified as a sustainable activity, which is why it is 
necessary to extrapolate this concept. There is no definition of sustainability that is universally adopted by the mining industry. Discussions on this topic are numerous, but there are difficulties in applying sustainable development strategies in mining, the reasons given being the multitude of interpretations of this concept of sustainable development.

Applying sustainable practices in the mining industry can sound like an oxymoron. Although the two terms are seemingly incompatible, as long as we do not end the consumption of resources, mining will never end. Businesses involved in the extraction of non-renewable resources are under great pressure to implement the concept of sustainability in strategic decision-making processes and operations. Thus, responsible companies have developed a number of initiatives aimed at ensuring good management of economic, environmental impact, and social responsibility. At the same time, relations between government, industry, and other stakeholders must be productive.

Thus, the best way for the mining industry to coexist with the environment for the purpose of sustainable development of society from all points of view is to establish and implement the best sustainable practices applied in conditions of maximum safety and to focus on achieving favorable results from the point of view of the economy, the environment, and the community.

Sustainable development in mining implies the existence of capable management and making commitments on improving the environment, the economy, and society, throughout the project and up to the closing and post-closing stages of the activity. The need to redefine this concept of "sustainable development", so as to include in its sphere the extractive industry, is even greater as it is clear to us that ceasing any mining activity is not a feasible choice, while mankind has and will continue to need raw material.

\subsection{Coal production}

Kippenberger presented the annual production of mineral and energy resources in the form of a pyramid [10]. This pyramid was made on the basis of data obtained in 1998 on world production of mineral and energy resources when the world's population exceeded 6 billion inhabitants. Two decades later, the world's population exceeded 8 billion, increasing production and resource consumption.

Analyzing this pyramid, which indicates a hierarchy in terms of resources, we can see a pattern, so that the resources at the base of the pyramid provide us the necessary materials for infrastructure development, fuel provides heating and transport, and those at the top of the pyramid, much rarer and more expensive, are used in various applications for the development of technology, being essential in the electronic components of the technology industry [11].

Mineral fuels occupy leading places, coal and lignite being, according to quantity, on the $3^{\text {rd }}$, respectively $6^{\text {th }}$ place in the world. The current production $(2019)$ is impressive, about 7.9 billion tons. It is understood that current production has increased with the population explosion.

Based on existing data $[12,13]$, the average multiannual coal production achieved globally in the period 1984-2018 was determined. It was found that the multiannual average is 5.66 billion tons of coal, of which: 4 billion tons of steam coal, 0.95 tons of lignite, and 0.71 billion tons of coking coal.

According to the latest statistics, made in 2020 [12], and referring to the average multiannual production, it is found that Romania contributes to world coal production in a proportion of about $0.4 \%$. In terms of the amount of coal produced nationally, our country is based on lignite production, with an average annual production of about 24 million tons. 


\subsection{Availability of coal resources}

The availability of resources is estimated using the concept of "resource lifespan", which is defined as the ratio between the known reserves and the annual consumption. This estimate is influenced by several factors such as the type of deposit, the distribution of the reserve in relation to the size of the deposit, the cost, the price level, the intensity of exploration, and the development of technology.

According to the 2020 report, world coal reserves amounted to 1074 billion tonnes and are strongly concentrated in the US (23\%), Russia (15\%), Australia (14\%), and China $(13 \%)$. The current reserve-to-production $(\mathrm{R} / \mathrm{P})$ ratio shows that the lifespan of economically exploitable coal reserves is about 139 years. Romania holds less than $0.05 \%$ of world reserves, covering the country's needs for a short time - 19 years [13].

In the Romanian subsoil there are all types of humic coal, including peat (in the intramountain depressions of the Eastern Carpathians: Ciuc depression - Miercurea Ciuc, Siculeni and Toplița; Maramureș depression - Ocna Șugatag; Giurgeului depression Remetea; Bârsa depression; Transylvania Basin; Harghita, Călimani, Gutâiului, Bârgăului, Apuseni Mountains, etc.), lignite (in Oltenia, in Muntenia and in some intramontane basins; Bahna-Orșova Depression; Brașov Depression; Pannonica Depression), brown coal (in Codlea-Vulcan, Almaș-Agrij basins, Țebea-Brad, Comănești), hard coal (in Jiu Valey, Rusca Montană, Anina basins. etc.), anthracite coal (Dragosela-Tulinberg-Baia Nouă deposit) and anthracite (Schela-Viezuroiu deposit). Lignite has the largest share of energy coal reserves, over $85 \%$.

\section{Results and discussions}

Following the accession to the European Union, Romania and the other Member States have the obligation to respect and implement the proposals found in the EU directives. For Romania, it seems that these are no obligations. Moreover, Romania immediately embraced these initiatives, giving them special importance, so that the results expected by the EU were not long in coming in terms of the contribution of energy policies to reducing the impact of climate change. Romania has reached the targets in advance:

-in 2012 it registered a reduction of $47.96 \%$ of greenhouse gas emissions compared to the reference year 1990 and to $20 \%$ assumed;

-in 2016 it registered an increase by $25.03 \%$ of the share of energy from renewable sources in gross consumption, compared to $20 \%$ assumed;

-in 2016 it registered a reduction of energy consumption by $41.6 \%$, compared to $20 \%$ assumed;

-implemented the National Action Plan in the field of energy efficiency;

-implemented the Green House Program to support energy saving by thermal rehabilitation of buildings and installation of heating systems based on renewable energy resources, etc.

\subsection{The Romanian energy mix - Past - present - future}

In recent years, the share of energy sources in the national energy system has undergone major changes. From the Figure 2 (a. during winter and b. during summer), it can be seen how coal, once the main energy source of the country, came from the first place on the $2^{\text {nd }}$, $3^{\text {rd }}$ and even $4^{\text {th }}$ places in importance in the energy mix.

According to the Romanian Energy Strategy 2019-2030 [16], the targets for 2030 are: expansion of electricity transmission and distribution networks, ensuring access to energy 
at acceptable prices, increasing the share of renewable energy sources (including in the transport sector), increasing energy efficiency, ensuring the security of energy systems. etc.

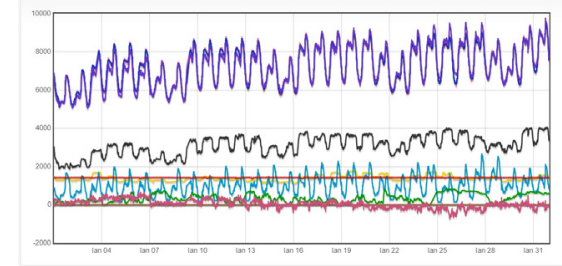

January 2012

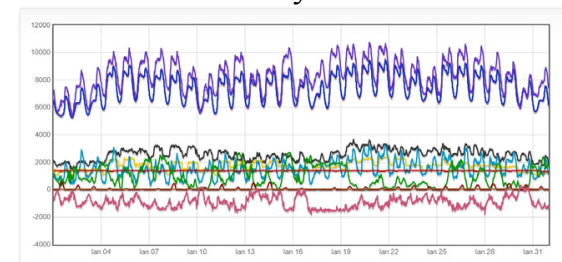

January 2016

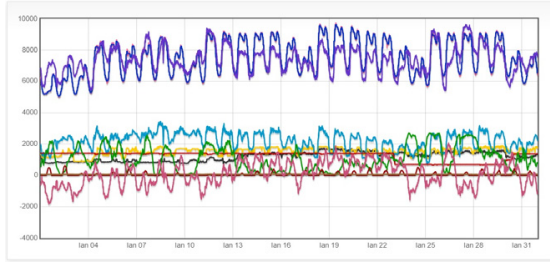
January 2021

Consumption
Hydrocarbs
$\square$ Photo
Average hourly consumption
$\square$ Waters
Biomass

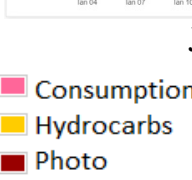

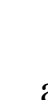

a.

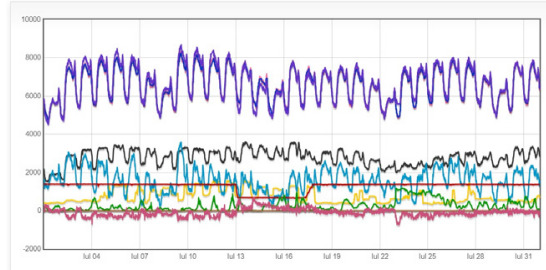

July 2012



July 2016

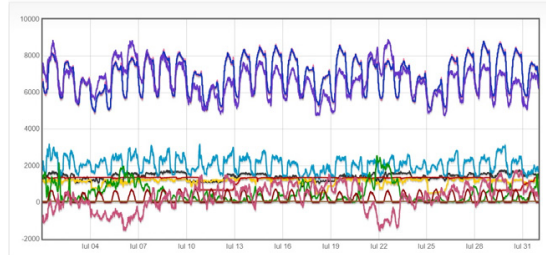

July 2021

$\begin{array}{ll}\square \text { Production } & \square \text { Coal } \\ \square \text { Nuclear } & \\ \text { Sold } & \text { Wind }\end{array}$

(MWh)

b.

Fig. 2. Changes in the Romanian energy mix (2012 - 2016 - 2021) [15].

In the perspective of 2050, the Romanian energy mix will be a diversified, balanced and modern one. A diversified energy mix means, from our point of view, a strategic mix consisting of both renewable and non-renewable sources, used rationally so as to ensure the country's security and environmental health.

\subsection{What if coal would disappear from the energy mix in Romania?}

Though, all the present actions aimed at reducing the impact on the environment and even the problem of depletion of coal reserves indicate a high probability of coal disappearance from the Romanian energy mix, Romania is a developing country and such action can lead to the country's regression. Therefore, we are entitled to ask ourselves this question: "What if coal would disappear from the Romanian energy mix?".

The implications, considered by us (which the disappearance of coal from the energy mix could have), were transposed in 3 scenarios:

Scenario no. 1 - Probable and favorable: Replacing coal with renewable energy sources, zero emissions. 
Scenario no. 2 - Probable and unfavorable: Replacing coal with economically viable sources, but generating emissions even if at a lower level (non-renewable sources: oil, gas, nuclear).

Scenario no. 3 - Undesirable: The impossibility to cover the energy demand from the existing resources and the dependence of the national system on imports. At least until 2024, when the construction of the 2 new reactors from Cernavodă Nuclear Power Plant is expected to be completed, coal-fired thermal power plants will continue to operate in Romania. Once put into operation, the two new reactors will more then double the current installed power of the Cernavodă plant, so that they will be able to supply the necessary energy when the coal mines and thermal power plants are closed.

Of the 3 scenarios, only 2 are considered viable so further, the first and second scenarios are presented and analyzed by the SWOT (strengths, weaknesses, opportunities, and threats) analysis method. SWOT analysis method is a planning tool, used to identify and analyze strengths, weaknesses, opportunities, and threats of products, services or organizations, in a way that allows decision making and help develop strategic goals.

\subsubsection{Scenario no. 1 - Probable and favorable: Replacing coal with renewable energy sources, zero emissions}

The energy transition, a global process, involves the creation of a sustainable energy system by gradually replacing fossil fuel-based electricity production with renewable energy production, with the aim of reducing greenhouse gas emissions that contribute to increasing greenhouse effect and implicitly to climate changes.

Replacing coal with renewable energy sources would be the most favorable option as it would meet the objectives of the European Green Deal, which aims to reduce environmental pollution and restore biodiversity by investing in clean technologies.

Currently, the electricity in the national mix comes from renewable and non-renewable sources. Renewable sources contribute to the current national energy production in the following proportions: hydropower $\approx 27.8 \%$, photovoltaic $\approx 2.4 \%$, biomass $\approx 0.9 \%$, and wind $\approx 12.5 \%[15]$.

According to the National Meteorological Administration (ANM) [17], Romania has a huge energy potential due to its geographical position and resources, but it has an uneven distribution, as follows: Danube Delta - solar energy; Dobrogea - solar and wind energy; Moldova - micro-hydro, wind energy, and biomass; Carpathian Mountains - high potential for biomass and micro-hydro; Transylvania - high potential for micro-hydro; Western Plain - geothermal and solar energy; Subcarpathians - potential for biomass and micro-hydro; Romanian Plain - biomass, geothermal and solar energy.

If this scenario materializes, a unitary management system in the energy industry could ensure the reduction of environmental pollution, jobs, welfare and economic development. Mining tourism can be developed in the former mining regions, an area of growing global interest.

The major disadvantages in the implementation of this scenario refer especially to the following aspects:

- damage to energy systems due to extreme weather events, thus generating significant material losses;

- an unfavorable ratio of redundancies in the mining sector - employment in the green energy sector as a result of the fact that coal mines and thermal power plants close more sooner than the opening of power plants on renewable sources;

- reduction of the labor force as a result of technological development etc.

Table 1 presents the results of the SWOT analysis performed for scenario 1. 
Table 1. SWOT analysis for scenario no. 1.

\section{S TrengthS}

Environmental and health protection

Access to environmentally sustainable solutions

Use of modern knowledge to ensure economic and investment efficiency

Close to zero waste in the operation stage

The existence of clean technologies

Exchange of experiences and professional retraining

Openness to the accumulation of new knowledge and skills

Decent jobs and living standards due to attractive salaries

Ensuring equity and social cohesion

\section{Opportunities}

Economic prosperity, by promoting knowledge, innovation, and competitiveness to ensure high living standards and well-paid jobs

Equity and social cohesion, by respecting fundamental rights, cultural diversity, equal opportunities, and by combating discrimination of any kind

Informing and actively involving citizens in the decision-making processes

Involvement of the business environment and the social partners

Possibility of being the first or among the first countries to achieve the objectives of the European Union

Development of mining tourism and mining archaeology

\section{WEAKNESSES}

Poor infrastructure

High costs and lack of secure sources of funding for the development of renewable energy infrastructure

Land occupation and change of land use

Policy coherence and quality of governance at local, regional, national level

Integration of economic, social, and environmental policies through impact assessments and stakeholder consultation

Fewer jobs (and more accessible to men) if the closure of mines and thermal power plants is not properly correlated with the opening of renewable power plants Changing jobs and distance from home may require commuting, may cause stress to certain individuals

\section{Threats}

Unfavorable weather conditions (drought, floods, storms, strong winds or lack of wind, hail, etc.) can affect production or even destroy energy production systems (breaking dams in case of exceptional floods, destroying solar panels in case of large hail, destruction of wind turbines in case of storms or tornadoes, etc.)

Reduction of labor - major consequence of technological development

The layout of a large number of employees in the coal sector

Difficulties in securing a job for each miner

An influx of migrant workers

Loss of cultural and traditional values

\subsubsection{Scenario no. 2 - Probable and unfavorable: Replacing coal with economically viable sources, but generating emissions even if at a lower level (non-renewable sources: oil, gas, nuclear)}

The second possible scenario, given the disappearance of coal from the energy mix, is that coal is replaced by economically viable sources, which are also non-renewable sources with emissions in the case of gas and oil, respectively risks in the case of nuclear power plants, such as the risk of nuclear explosions, the risk of terrorist attacks, and health risks. Romania has significant reserves of gas, oil, and even uranium (although the Crucea mine will be closed due to depletion of reserves, it is intended to open the Tulghes Greties field). A plus for this scenario is that it involves the use of tested technologies for energy production, which leads to relatively low operating and recovery costs. It should also be noted that these sources are a balancing factor of the energy system when hydro or wind energy registers minimum values as a result of the prolonged drought or atmospheric calm etc.

This scenario is considered unfavorable as a result of the impact on the environment and the tendency of irrational exploitation of non-renewable resources, which leads to their exhaustion.

Non-renewable sources contribute to the current national energy mix in the following proportions: coal $\approx 17.4 \%$, nuclear $\approx 20.7 \%$, and hydrocarbons $\approx 18.3 \%$ [15]. In order to replace coal with another source, it is mandatory to expand current perimeters or to open new ones for the exploitation of hydrocarbons and uranium, so implicitly to change the direction of land use. 
The impact on the environment can be significantly reduced through new low-emission, economically and energy-efficient technologies. If the reserve-production ratio is maintained in line with the idea of sustainability, losses of raw materials and energy are reduced, products are designed with a long life as possible, the degree of recycling and reuse of waste for energy production increases, then scenario 2 can become acceptable.

Table 2 presents the results of the SWOT analysis performed for scenario 2 .

Table 2. SWOT analysis for scenario no. 2.

\section{S Trengths}

Significant reserves of oil, gas, uranium Possibility of extending existing exploitation perimeters or opening new perimeters for uranium, gas and oil exploitation

Relatively low operating and capitalization costs Openness to the accumulation of new knowledge and skills

Medium and long term jobs and significant sources of income

Means of economic development, felt especially at the local level

\section{Opportunities}

New and clean technologies (low emissions), economically and energy efficient

Modernization of extraction-production processes

Maximum reduction of environmental impact

Concentration of activities in mining perimeters with potential for economic efficiency

Reducing energy and raw material losses

The development of mining in harmony with the environment through the rational use of resources

Maintaining a correct reserve-production ratio taking into account the concept of sustainable development and capitalizing as much as possible on renewable energy resources

Efficiency of processes from a technical-economic point of view

Making productive investments favoring the long-term development of the country

Communication and active participation in decisionmaking in the hope of building a better future for all decision-makers, including local communities

\section{WeaKnesses}

The intense capitalization of non-renewable resources accentuates the tendency of depletion

Waste

Maintaining exports

Little experience related to the rational management of resources, lack of knowledge and stimulants needed to turn investments into profit

Unclear legislation regarding the restoration of the environment in the mining-affected areas

Removing some land areas from the ecological circuit and even displacing the population in case of opening new exploitation perimeters

\section{Threats}

Difficulties in the management of waste from nuclear power plants

Social problems caused by the cessation of exploitation, the closure of coal-fired power plants or vice versa, the possibility of developing tense relations and conflicts between the community and the management of new mines

The existence of a corrupt government

Lack of transparency in decision-making processes

In the desire for immediate gains, the country's resources are sold at low prices

Exhaustion of the country's resources in favor of those who buy their resources

Difficulties in the development of the country

Poverty

Difficulties in aligning with European standards

Negative impact on the environment and health

Sanctions from EU

However, we do not know to what extent Europe's effort will have an influence on the global balance, given that in countries such as the USA, China, Indonesia or Australia, the trend regarding coal production/consumption ratio is stagnant or increasing, and, to some extent, implicitly the GHG emissions.

\section{Conclusions}

Romania, a country rich in resources, benefits from numerous potential substitutes for coal, both renewable and non-renewable.

The implications of the disappearance of coal from the Romanian energy mix have been transposed into 3 scenarios, two of which are considered to be probable, and one undesirable: scenario no. 1 - probable and favorable: Replacing coal with renewable energy sources, zero emissions, scenario no. 2 - probable and unfavorable: Replacing coal with 
economically viable sources, but generating emissions even if at a lower level (nonrenewable sources: oil, gas, nuclear), and scenario no. 3 - undesirable: The impossibility to cover the energy demand from the existing resources and the dependence of the national system on imports. The 2 probable scenarios, of which one favorable and one unfavorable in the context of sustainable development and environmental protection, were analyzed using the SWOT method. Following the SWOT analysis, it was observed that both probable scenarios could take shape, with important benefits and opportunities for the socio-economic development of the country and for the protection of the environment.

There is always the issue of financial resources, so necessary to make these changes. Although in terms of environmental protection and reducing the current level of pollution, scenario 1 is more favorable than scenario 2 , if we analyze financially, the situation is the opposite: the materialization of scenario 1 requires higher investment than scenario 2 . It remains to find the sources necessary to finance scenario 1 , in which case Romania can become an eco country, and otherwise, by implementing scenario 2 and new and modern technologies, Romania would benefit from a cleaner environment. The total replacement of coal as an energy resource is theoretically possible, but this involves a transition period that must ensure the construction and/or expansion of the necessary infrastructure for the procurement of raw materials and effective energy production. Given the importance of maintaining (regaining) energetic security, it is necessary to think of a complex process containing the steps and measures necessary to ensure a just transition, so that the economy and the population are free from technical or financial shocks.

\section{References}

1. Ministry of Environment and Sustainable Development, Romania's National Strategy for Sustainable Development, Horizons 2013-2020-2030 (Bucharest, 2008)

2. D.H. Meadows, D.L. Meadows, J. Randers, W.W. Behrens the III, The limits to growth (Potomac Associates - Universe Books, United States of America, 1972)

3. World Commission on Environment and Development, Our common future (Oxford University Press, Oxford; New York, 1987)

4. United Nations General Assembly, Agenda 21 (United Nations, 1992)

5. United Nations General Assembly, Report of the World Summit on Sustainable Development (Johannesburg, 2002)

6. European Commission, Treaty of Lisbon amending the Treaty on European Union and the Treaty establishing the European Community, Off. J. of the EU, Lisbon, Portugal (2007)

7. United Nations General Assembly, Transforming our World: The 2030 Agenda for Sustainable Development (United Nations, 2015)

8. European Commission, Towards a circular economy: A zero waste programme for Europe (Bruxelles, 2014)

9. European Commission, The European Green Deal (Bruxelles, 2019)

10. C. Kippenberger, Materials flow and energy required for the production of selected mineral commodities, Summary and conclusions, Geo. Yearbook, Series H (13), 55 (2001)

11. F.W. Wellmer, J.D. Becker-Platen, Proceedings for a Workshop on Deposit Modeling, Mineral Resource Assessment, and Their Role in Sustainable Development, U.S. Geological Survey Circular 1294, 1 - 16, Reston Virginia (2007)

12. International Organizing Committee for the World Mining Congresses, World Mining Data 2020, Federal Ministry Republic of Austria, Agriculture, Regions and Tourism (Vienna, 2020)

13. F. Faur, M. Lazăr, E. Dunca, D.I. Ciolea, Critical analysis of the trends in use of classical energetic resources, SGEM2015 Conference Proceedings 3, 163-170 (2015)

14. BP, Statistical Review of World Energy $2021,70^{\text {th }}$ edition (2021)

15. Transelectrica, România. https:/www.transelectrica.ro/widget/web/tel/sen-grafic//SENGrafic_WAR_SENGraficportlet Accessed on 12.07.202

16. Romania's national strategy for sustainable development 2030 (Paideia, Bucharest, 2018)

17. National Meteorological Administration, Romania (2021) 